\title{
High clustering rates of multidrug-resistant Mycobacterium tuberculosis genotypes in Panama
}

\author{
Samantha Rosas ${ }^{1,4}$, Jaime Bravo1, Franklin Gonzalez ${ }^{1}$, Nora de Moreno ${ }^{2}$, Joel Sanchez ${ }^{3}$, Ronnie G Gavilan ${ }^{3}$ \\ and Amador Goodridge ${ }^{4^{*}}$
}

\begin{abstract}
Background: Tuberculosis continues to be one of the leading causes of death worldwide and in the American region. Although multidrug-resistant tuberculosis (MDR-TB) remains a threat to TB control in Panama, few studies have focused in typing MDR-TB strains. The aim of our study was to characterize MDR Mycobacterium tuberculosis clinical isolates using PCR-based genetic markers.

Methods: From 2002 to 2004, a total of 231 Mycobacterium tuberculosis isolates from TB cases country-wide were screened for antibiotic resistance, and MDR-TB isolates were further genotyped by double repetitive element PCR (DRE-PCR), (GTG)5-PCR and spoligotyping.

Results: A total of 37 isolates (0.85\%) were resistant to both isoniazid (INH) and rifampicin (RIF). Among these 37 isolates, only two (5.4\%) were resistant to all five drugs tested. Dual genotyping using DRE-PCR and (GTG)5-PCR of MDR Mycobacterium tuberculosis isolates revealed eight clusters comprising $82.9 \%$ of the MDR-TB strain collection, and six isolates (17.1\%) showed unique fingerprints. The spoligotyping of MDR-TB clinical isolates identified $68 \%$ as members of the 42 (LAM9) family genotype.
\end{abstract}

Conclusion: Our findings suggest that MDR Mycobacterium tuberculosis is highly clustered in Panama's metropolitan area corresponding to Panama City and Colon City, and our study reveals the genotype distribution across the country.

Keywords: Mycobacterium tuberculosis, Multidrug-resistant tuberculosis (MDR-TB), DRE-PCR, (GTG)5-PCR, Spoligotyping

\section{Background}

Mycobacterium tuberculosis (M. tuberculosis) is the bacterium that causes tuberculosis (TB), which is the world's leading infectious killer after human immunodeficiency virus (HIV). TB itself kills around 1.4 million people annually with virtually all deaths occurring in developing countries [1]. TB control has been impaired by the persistence of multidrug-resistant $M$. tuberculosis (MDR-TB). In 2011, Panama reported 1301 new pulmonary TB cases, including an estimated seven MDR-TB cases [2]. The estimated average prevalence of MDR-TB in Panama for 2011 was approximately $0.5 \%$; however, a more detailed country-wide surveillance project is now underway [2]. Also, novel diagnosis and biomarker tests for monitoring the treatment response in MDR-TB cases are currently under evaluation.

\footnotetext{
* Correspondence: agoodridge@indicasat.org.pa

${ }^{4}$ Centro de Biología Celular y Molecular de Enfermedades, Instituto de Investigaciones Científicas y Servicios de Alta Tecnología (INDICASAT-AIP), Ciudad Del Saber, Panama, Panama

Full list of author information is available at the end of the article
}

MDR-TB case surveillance and control in Panama currently rely on conventional epidemiology tools. Presently, the health care system interviews MDR-TB-affected patients to collect demographic characteristic information, as recommended by WHO [3]. In addition, information about past history of TB and treatment, type and extent of disease, concomitant medical illnesses and substance abuse, among others risk factors, is also collected. However, investigation of these MDR-TB patients' contacts remains limited, and thus, conventional epidemiology findings are unable to prove true links between most MDR-TB cases $[4,5]$. Consequently, the National TB Program (NTBP) continues to invest enormous time and effort to determine transmission dynamics within communities in order to implement appropriate strategies for TB and MDR-TB control and prevention.

For more than a decade, researchers have demonstrated the use of genomic markers to study TB and MDR-TB epidemiology as a useful strategy for understanding $\mathrm{TB}$ 
transmission dynamics [6]. Rapid and inexpensive genotyping based on PCR assays, such as double repetitive element PCR (DRE-PCR) and (GTG)5, have proven to be useful in determining the genetic relationships and epidemiology of $\mathrm{TB}$ and MDR-TB within vulnerable communities; these genotyping techniques identify and track individual $M$. $t u-$ berculosis strains [7-13]. Similarly, spoligotyping is a wellestablished commercial method that provides worldwide standardized information about M. tuberculosis isolates' family lineage background [14-17]. However, despite these laboratory improvements, data on the transmission and distribution of MDR M. tuberculosis strains within Panama remain scarce. Therefore, our study aimed to characterize the distribution of MDR M. tuberculosis isolates from the Republic of Panama collected between 2002 and 2004 using DRE-PCR and (GTG)5-PCR in a dual genotyping strategy and spoligotyping.

\section{Methods}

\section{MDR M. tuberculosis clinical isolates}

M. tuberculosis isolates from 231 suspected multidrugresistant pulmonary $\mathrm{TB}$ cases were collected between January 2002 and December 2004 from local laboratories at nine different health centers and hospitals located throughout the Republic of Panama. Because the strain collection was performed as part of the Panamanian standard of patient care for TB diagnosis and control, this study was not submitted to ethical committee evaluation. The identification of $M$. tuberculosis isolates was performed using biochemical tests including niacin, nitrate and catalase tests [18]. All isolates were evaluated for antibiotic resistance on Lowenstein-Jensen (LJ) medium according to the Cannetti proportion method [19]. Briefly, a suspension of $M$. tuberculosis clinical isolate was placed in an LJ tube with and without drugs. M. tuberculosis colony forming units (CFUs) were enumerated in the drug-free medium (control tubes) and in the tubes with anti-tuberculosis drugs. Each LJ media tube contained a single antibiotic at the following concentrations: $0.2 \mathrm{mg} / \mathrm{ml}$ isoniazid (INH), $40 \mathrm{mg} / \mathrm{ml}$ rifampicin (RFP), $4 \mathrm{mg} / \mathrm{ml}$ streptomycin (SM), $2 \mathrm{mg} / \mathrm{ml}$ ethambutol (EMB) and $2 \mathrm{mg} / \mathrm{ml}$ paraminosalicylic acid (PAS). The resistance percentage was calculated by multiplying the ratio of the CFUs in media with drugs to the CFUs in media without drugs by 100 . No growth in the LJ medium with anti-tuberculosis drugs indicated a sensitive strain. M. tuberculosis isolates that were resistant to at least rifampicin and isoniazid were classified as MDR M. tuberculosis and stored in 10\% skim milk (Difco, USA) at $-70^{\circ} \mathrm{C}$ until further DNA extraction and genotyping.

DNA isolation from MDR M. Tuberculosis clinical isolates DNA was extracted from $M$. tuberculosis isolates with Chelex ${ }^{\circ}$ using a method described previously [20,21].
Briefly, two or three colonies were inactivated at $80^{\circ} \mathrm{C}$ for $30 \mathrm{~min}$ in Tris-EDTA $(10 \mathrm{mM}$ Tris, $1 \mathrm{mM}$ EDTA, $\mathrm{pH}$ 7.4) buffer and then immediately placed on ice. Then, the bacteria were centrifuged at 10,000 rpm for two min. The supernatant was then discarded and the pellet resuspended in $500 \mu \mathrm{l}$ of $5 \%$ Chelex-100. The suspensions were vortexed for a few seconds and incubated at $56^{\circ} \mathrm{C}$ for $20 \mathrm{~min}$, boiled at $100^{\circ} \mathrm{C}$ for $10 \mathrm{~min}$. and then placed on ice for two min. and centrifuged at 13,000 rpm for five min. The supernatant containing the DNA was stored at $-20^{\circ} \mathrm{C}$

\section{DRE-PCR genotyping}

Isolated DNA from MDR M. tuberculosis isolates was analyzed with a modified DRE-PCR protocol $[8,10]$. The PCR assays were performed in a $25-\mu$ l reaction volume containing three $\mu \mathrm{l}$ of the extracted DNA, Go-Taq Green Master Mix (Promega Corporation, USA) supplemented with 4.5 Mm MgCL2, 6\% dimethyl sulfoxide (DMSO), 1 U Taq DNA polymerase (Bioselec S.A., Mexico D.F.) and the four primers Ris1, Ris2, Pntbl and Pntb2 at 25 pmol each as previously described [10]. The PCR was performed as described by Friedman et al., including an additional ramp of $+0.7^{\circ} \mathrm{C}$ per second between the denaturation and annealing segments [10]. PCR products were analyzed by electrophoresis on $2 \%$ agarose gel and visualized with ethidium bromide in a gel documentation system (Ultra-Lum Omega System, USA).

\section{(GTG)5-PCR genotyping}

DNA fingerprinting of MDR M. tuberculosis was carried out using a modification of previously described protocols [12,22]. Briefly, DNA samples from MDR M. tuberculosis strains were subjected to rep-PCR using the (GTG)5 primer (5' -GTGGTGGTGGTGGTG-3'). The PCR assays were performed in a $50-\mu \mathrm{l}$ reaction volume containing 10 ng of genomic DNA, one unit of Taq DNA polymerase (Roche, Mannheim, Germany), $0.8 \mathrm{mM}$ of the (GTG) 5 primer (Sigma-Aldrich, St. Louis, MO), $1.5 \mathrm{mM} \mathrm{MgCl} 2$ and $200 \mu \mathrm{M}$ of each deoxynucleoside triphosphate (Roche, Mannheim, Germany). PCR cycling conditions consisted of initial activation at $94^{\circ} \mathrm{C}$ for five min, followed by 35 cycles of a three-step PCR program $\left(94^{\circ} \mathrm{C}\right.$ for 45 seconds, $40^{\circ} \mathrm{C}$ for one min. and $65^{\circ} \mathrm{C}$ for $10 \mathrm{~min}$.) and a final extension at $65^{\circ} \mathrm{C}$ for $20 \mathrm{~min}$. PCR products were analyzed by electrophoresis on $1.2 \%$ agarose gel and visualized with ethidium bromide.

\section{Spoligotyping genotyping}

Spoligotyping was performed on genomic DNA using the standard method described by Kamerbeek et al. [14]. Spoligotypes were reported in standard international type number (SIT) and octal code numbers were obtained from the SPOLDB4.0 [23]. 


\section{Data analysis}

The fingerprints obtained using both DRE-PCR and (GTG)5-PCR were analyzed using Bionumerics Software version 6.6 (Applied Maths, Sint-Martens-Latem, Belgium). Band patterns were evaluated using the Dice similarity coefficient with a $4 \%$ band tolerance and $1 \%$ of optimization. Dendograms were constructed using the unweighted pair group method with arithmetic mean (UPGMA). Related strains in a cluster were defined as having more than $90 \%$ of homology. The similarity between (GTG)5-PCR and DRE-PCR was calculated using the Pearson correlation coefficient ( $\mathrm{r}$ value) using Bionumerics Software.

\section{Results}

From 2002 to 2004, the Panamanian NTBP reported a total of 4507 new pulmonary TB cases country-wide. Of those new cases, $231 \mathrm{M}$. tuberculosis clinical isolates were sent to Laboratorio Central de Referencia de Salud Pública de Instituto Conmemorativo Gorgas de Estudios de la Salud (LCRSP-ICGES) for drug susceptibility testing (DST). At least 69\% (160) of these isolates were originally obtained from the metropolitan region, including San Miguelito, Panama Este, Panama Oeste and Colon City. The DST results revealed monoresistance to INH (29.0\%), RFP (30.7\%), SM (22.1\%), EMB (8.2\%) and PAS $(0.9 \%)$ in the collection of $231 \mathrm{M}$. tuberculosis isolates. Thirty-seven isolates collected between 2002 and 2004 demonstrated resistance to at least INH and RFP, and these isolates were defined as MDR Mycobacterium tuberculosis. Thus, an average prevalence for the threeyear period is estimated at $0.82 \%$ of the total national TB cases reported (Figure 1). These 37 MDR M. tuberculosis isolates were not distributed uniformly across Panama. Colon City itself accounted for $40 \%$ of the MDR-TB cases, whereas Chiriqui and the Metropolitana region accounted for $23 \%$ and $20 \%$, respectively (Table 1 ). Within these 37 MDR-TB isolates, 76\% (28 isolates) were resistant to INH, RIF and SM. Only 5.4\% (two isolates) of the MDR-TB isolates showed resistance to all five drugs

The combined analysis of DRE-PCR and (GTG)5-PCR showed a high clustering of MDR M. tuberculosis clinical isolates in the Colon and Metropolitana regions of Panama. Fourteen different DRE-PCR patterns were obtained with a range of two to eight bands. In contrast, (GTG)5-PCR showed six different patterns with a range of eight to fifteen bands. Two MDR M. tuberculosis isolates did not amplify and were excluded from the clustering computer analysis (Figure 2). A comparison between both methods revealed only a $15.3 \%$ correlation (Pearson $p=0.0424$ ). Therefore, we assigned a genotype to each strain using both methods in a dual typing strategy. The dual genotyping identified Cluster A, which consisted of six out of the 35 isolates (17.1\%). In this cluster, four

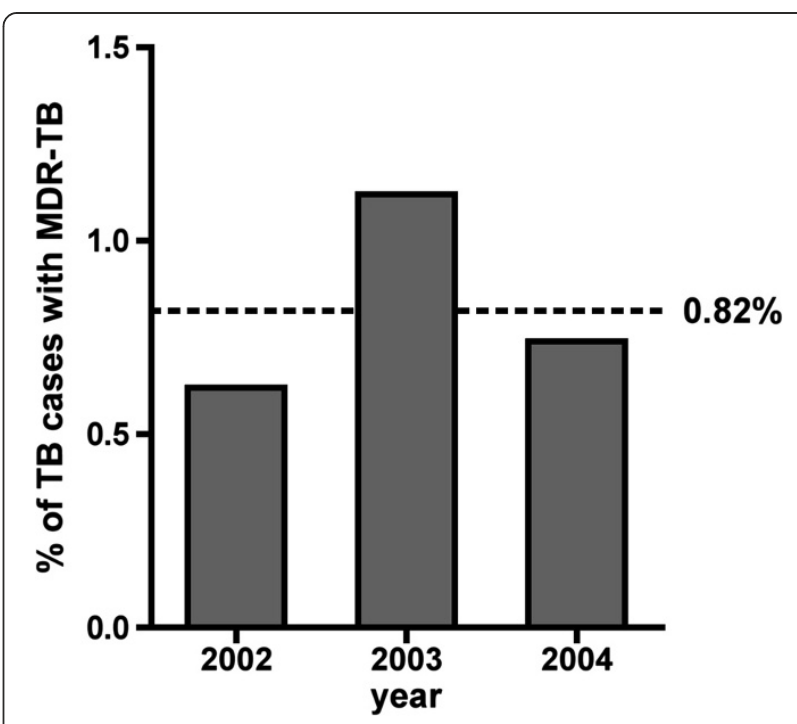

Figure 1 Proportion of MDR-TB cases in Panama from 2002 to 2004. Country-wide M. tuberculosis clinical isolates were evaluated by the Canetti drug susceptibility test between 2002 and 2004. Thirty-seven isolates were multidrug-resistant (MDR). The bars show the percentage of MDR M. tuberculosis strains per year. The dotted line indicates the countrywide average proportion of TB cases with MDR-TB for the three-year period.

strains were isolated from Colon City and one was isolated from Chiriqui. Cluster B included eight isolates (22.9\%), six from Colon City, one from the Metropolitana region and one from San Miguelito. Cluster C consisted of four isolates (11.4\%) from our MDR M. tuberculosis set. This cluster was composed of three isolates from the Metropolitana region and one from Chiriqui. Cluster $\mathrm{G}$ included 5.7\% (2/35) of MDR M. tuberculosis isolates, both from patients from the Colon region. Cluster $\mathrm{H}$ contained three out of the 35 isolates (8.6\%). Clusters I and J consisted of two isolates each $(5.7 \%)$, of which all four MDR M. tuberculosis cases were from the Chiriqui region. Finally, Cluster L included two isolates from Panama Este and two isolates from Panama Oeste. Six MDR $M$. tuberculosis isolates (17.1\%) were not grouped into the clusters described above (Figure 2).

The spoligotyping analysis typed almost $68 \%$ of MDR M. tuberculosis isolates as members of the 42 (LAM9) family. Remaining MDR-M. tuberculosis isolates were classified as spoligo international type (SIT) numbers 68, 46, 119, and 1366 according to the SPOLDB4.0 International Database (Table 1) [23]. We identified two MDR M. tuberculosis isolates that were not annotated in this database.

\section{Discussion}

During the 2002-2004 period, a collection of 231 M. tuberculosis isolates were identified to have monoresistance to INH (29.0\%), RFP (30.7\%), SM (22.1\%), EMB (8.2\%) or 
Table 1 Resistance and genotype profiles of MDR M. tuberculosis clinical isolates in Panama 2002-2004

\begin{tabular}{lllll}
\hline Region & N (\%) & Resistance profiles & DRE-(GTG)5 clusters & Spoligo international types \\
\hline Colon & $15(40.5)$ & $\mathrm{a}, \mathrm{b}, \mathrm{c}$ & $\mathrm{A}, \mathrm{B}, \mathrm{G}, \mathrm{K}$ & $42,46,68$ \\
Chiriqui & $10(27.0)$ & $\mathrm{a}, \mathrm{b}, \mathrm{C}$ & $\mathrm{A}, \mathrm{C}, \mathrm{D}, \mathrm{F}, \mathrm{H}, \mathrm{l}, \mathrm{J}$ & 42,119, unknown \\
Metropolitana & $5(13.5)$ & $\mathrm{a}, \mathrm{b}$ & $\mathrm{B}, \mathrm{C}$ & 42,68 \\
Panama Oeste & $2(5.4)$ & $\mathrm{b}$ & $\mathrm{L}, \mathrm{E}$ & 46 \\
San Miguelito & $2(5.4)$ & $\mathrm{a}, \mathrm{b}$ & $\mathrm{B}, \mathrm{M}$ & 42,1366 \\
Panama Este & $1(2.7)$ & $\mathrm{b}$ & $\mathrm{L}$ & 119 \\
Changuinola & $1(2.7)$ & $\mathrm{a}$ & $\mathrm{H}$ & 17 \\
Veraguas & $1(2.7)$ & $\mathrm{a}$ & $\mathrm{N}$ & 42 \\
\hline
\end{tabular}

Note: Resistance profiles are classified as follows: a) INH, RFP; b) INH, RFP, SM; c) INH, RFP, SM, EMB.

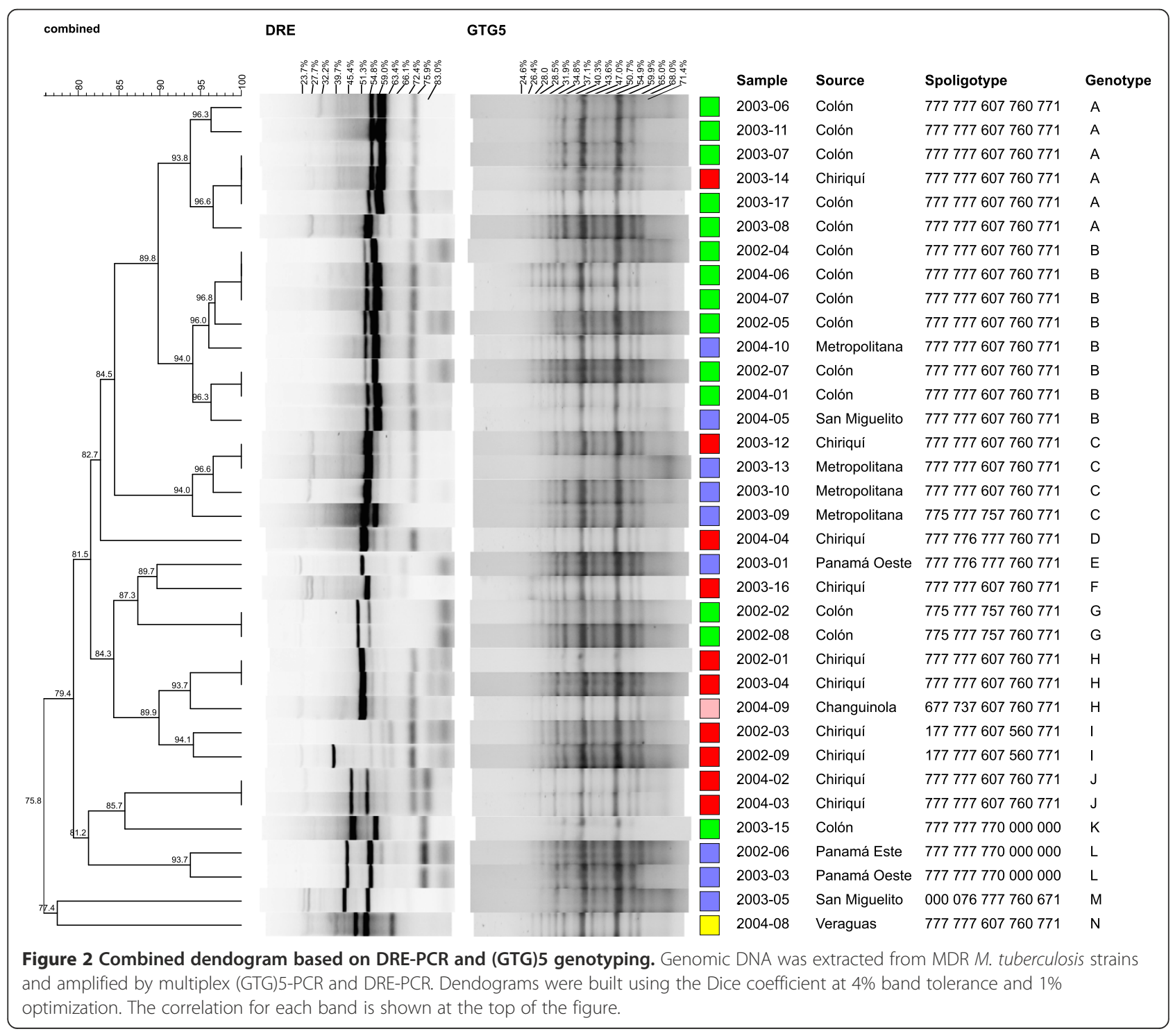


PAS (0.9\%). Thirty-seven $(0.82 \%)$ of these isolates were recognized as MDR $M$. tuberculosis because they were resistant to both INH and RFP drugs. Among these MDR M. tuberculosis isolates, two (5.4\%) were resistant to all five drugs. Our study results show that nearly $83 \%$ of these MDR M. tuberculosis cases were grouped within Panama City and Colon City, indicating a higher clustering rate compared to other cities in the Latin American region, such as $39.4 \%$ reported in Havana and $55.3 \%$ reported in Rio de Janeiro [8,24]. Specific molecular cluster patterns were found to be prevalent in Colon, San Miguelito and the Metropolitana region within the Republic of Panama. Colon City harbored the two largest clusters identified in this strain collection (Cluster A and B). Similarly, the MDR M. tuberculosis strains recovered from the Chiriqui region were clustered. These findings suggest that these MDR $M$. tuberculosis strains were spread rapidly during the period from 2002 to 2004.

Our data indicate that the Colon region has the highest number of clustered MDR M. tuberculosis isolates. One plausible explanation is the high TB incidence rate, which reached nearly 100/100,000 inhabitants in Colon during the study period [25]. In addition, the HIV-TB coinfection rate was up to $40 \%$ during those years. These two factors combined with Colon's lower socioeconomic status, extreme poverty levels and overcrowded living conditions might favor the transmission of MDR M. tuberculosis strains. New collaborative interventions to reinforce the TB-HIV response are currently being implemented by health authorities, INDICASAT-AIP and University Research Co., LLC (URC-CHS) to limit this situation, not only in Colon but across the entire Republic of Panama.

The overall high clustering rate found in our study indicates the possibility that patients belonging to a cluster might have been infected with an $M$. tuberculosis strain that easily became resistant. Another possible explanation is that an MDR $M$. tuberculosis mutant strain was selected by mono-therapy or irregular treatment compliance [26]. The exact reason for our findings remains to be explored by further combining bacterial genomics and patient epidemiological data. A recent study demonstrated the distribution of point mutations conferring resistance in a collection of MDR $M$. tuberculosis isolates from Panama using a multiplex PCR platform [27]. This study revealed that the most frequent point mutation is located in codon 315 of the KatG gene. However, it is expected that MDR M. tuberculosis isolates with a KatG gene mutation are likely to be clustered [28]. Molecular epidemiology studies using whole genome sequencing or VNTR-MIRU are now required to determine the extent of MDR-TB transmission and monitor the expansion of this infection, especially in the Colon region $[29,30]$.
The study of MDR-TB cases in Panama currently uses conventional epidemiology tools. The contact investigations for these MDR-TB cases remain limited, and conventional epidemiology results are unable to prove true links between most MDR-TB cases [4,5]. The use of PCR-based genotyping tools, such as those used in the present study, might be helpful in conducting the epidemiological contact investigation of MDR-TB cases in Panama $[8,10,11]$. Although DRE-PCR showed a poor correlation with (GTG)5 patterns in our study, a dual genotyping strategy using both techniques increased the accuracy when analyzing our MDR $M$. tuberculosis strain collection. Because the cost of PCR and primers has decreased, this dual strategy might be useful in settings without access to more expensive, cutting edge technologies.

The reasons for the persistence of MDR M. tuberculosis strains in Panama remain unknown. One explanation might be stochastic introduction resulting from migration for the Panama Canal construction at the end of the nineteenth century. Other plausible explanations include malnutrition, lack of adherence to anti-TB therapy and/or the intermittent availability of drugs. As depicted in our study, the spoligotype 42 (LAM9) was present in almost $68 \%$ of the MDR $M$. tuberculosis isolates studied. Despite Panama's geographical proximity to Valle de Cauca, Colombia, we did not find Beijing genotypes in the MDR-TB isolates from Panama [31]. Similarly, other studies in America have found wider genetic diversity when genotyping MDR M. tuberculosis strains using spoligotyping [15-17]. Our sample collection was not created under a systematic national MDR surveillance program; however, the findings indicate a need to redirect efforts in order to understand the transmission dynamics of MDR M. tuberculosis strains.

\section{Conclusion}

The findings presented here reveal that most MDR M. tuberculosis strains isolated from Panama City and Colon City are highly clustered. Our study confirmed the clustering of a limited number of MDR-TB cases using an inexpensive dual genotyping strategy; this strategy could be extended to countrywide MDR surveillance to gain a better understanding of MDR-TB transmission dynamics and contribute to MDR-TB control in the short term.

\section{Ethical approval}

The strain collection was performed as part of the Panamanian standard of patient care for TB diagnosis and control; thus, the study was not subject to ethical committee evaluation.

\section{Abbreviations}

TB: Tuberculosis; MDR: Multidrug-resistant; MDR-TB: Multidrug-resistant tuberculosis; NTBP: National tuberculosis control program; DRE-PCR: Double repetitive element - polymerase chain reaction. 


\section{Competing interest}

The authors declared that they have no competing interest.

\section{Authors' contributions}

SR, JB and FG performed the drug susceptibility tests. SR, AG and JS performed the genotyping. JS and RG performed the software-based fingerprint analysis. All authors wrote, edited and approved the manuscript.

\section{Acknowledgements}

We thank Dr. Chanti Polacek, Laura Flores and Colleen Goodridge for helpful discussions and critical review of this manuscript. Also thanks to the clinical laboratorists from Hospital Santo Tomás, Complejo Hospitalario Metropolitano, Hospital Manuel Amador Guerrero, Policlínica Hugo Spadafora de Colón, Hospital Regional de Chepo, Hospital Nicolás A. Solano, Hospital de Changuinola, Hospital Regional Rafael Hernández and Centros de Salud de San Miguelito, who kindly provided us with the M. tuberculosis clinical isolates for this study. This project was supported partially by the Network for Research and Training in Tropical Diseases in Central America (NeTropica) Grants No. 09-R-2003 and 05-N-2005 and by the ASM-SGM-IUMS travel training award 2005.

\section{Author details}

${ }^{1}$ Laboratorio Central de Referencia de Salud Pública, Instituto Conmemorativo Gorgas de Estudios de la Salud Pública, Vía Justo Arosemena, Panama, Panama. ²Departamento de Microbiología, Facultad de Medicina, Universidad de Panamá, Vía Transístmica, Panama, Panama. ${ }^{3}$ Centro de Biodiversidad y Descubrimiento de Drogas-Instituto de Investigaciones Científicas y Servicios de Alta Tecnología (INDICASAT-AIP), Ciudad Del Saber, Panama, Panama. ${ }^{4}$ Centro de Biología Celular y Molecular de Enfermedades, Instituto de Investigaciones Científicas y Servicios de Alta Tecnología (INDICASAT-AIP), Ciudad Del Saber, Panama, Panama.

Received: 10 April 2013 Accepted: 17 September 2013

Published: 23 September 2013

\section{References}

1. WHO: Global tuberculosis report. Geneve: Switzerland: World Health Organization; 2012

2. MINSA: Reporte nacional de tuberculosis. In Edited by Arango C. Panama: Ministerio de Salud; 2013.

3. WHO: Guidelines for the programmatic management of drug-resistant tuberculosis: emergency update 2008. Geneve: Switzerland World Health Organization; 2008

4. Daley CL: Transmission of multidrug-resistant tuberculosis: limited by man or nature? Am J Respir Crit Care Med 2002, 165(6):742-743.

5. Chan-Yeung M, Tam CM, Wong H, Leung CC, Wang J, Yew WW, Lam CW, Kam KM: Molecular and conventional epidemiology of tuberculosis in Hong Kong: a population-based prospective study. J Clin Microbiol 2003, 41(6):2706-2708.

6. Burgos MV, Pym AS: Molecular epidemiology of tuberculosis. Eur Respir J Supp/ 2002, 36:54s-65s.

7. Sola C, Horgen L, Maisetti J, Devallois A, Goh KS, Rastogi N: Spoligotyping followed by double-repetitive-element PCR as rapid alternative to IS6110 fingerprinting for epidemiological studies of tuberculosis. J Clin Microbiol 1998, 36(4):1122-1124.

8. Montoro E, Valdivia J, Leao SC: Molecular fingerprinting of mycobacterium tuberculosis isolates obtained in havana, cuba, by IS6110 restriction fragment length polymorphism analysis and by the double-repetitive -element PCR method. J Clin Microbiol 1998, 36(10):3099-3102.

9. Thierry D, Brisson-Noel A, Vincent-Levy-Frebault V, Nguyen S, Guesdon JL, Gicquel B: Characterization of a Mycobacterium tuberculosis insertion sequence, IS6110, and its application in diagnosis. J Clin Microbio/ 1990, 28(12):2668-2673.

10. Friedman CR, Stoeckle MY, Johnson WD Jr, Riley LW: Double-repetitiveelement PCR method for subtyping Mycobacterium tuberculosis clinical isolates. J Clin Microbiol 1995, 33(5):1383-1384.

11. Kremer $K$, van Soolingen D, Frothingham R, Haas WH, Hermans PW, Martin C, Palittapongarnpim P, Plikaytis BB, Riley LW, Yakrus MA, et al: Comparison of methods based on different molecular epidemiological markers for typing of Mycobacterium tuberculosis complex strains: interlaboratory study of discriminatory power and reproducibility. J Clin Microbio/ 1999, 37(8):2607-2618.

12. Wiid IJ, Werely C, Beyers N, Donald P, van Helden PD: Oligonucleotide (GTG)5 as a marker for Mycobacterium tuberculosis strain identification. J Clin Microbiol 1994, 32(5):1318-1321.

13. Kremer K, Arnold C, Cataldi A, Gutierrez MC, Haas WH, Panaiotov S, Skuce RA Supply P, van der Zanden AG, van Soolingen D: Discriminatory power and reproducibility of novel DNA typing methods for Mycobacterium tuberculosis complex strains. J Clin Microbiol 2005, 43(11):5628-5638.

14. Kamerbeek J, Schouls L, Kolk A, van Agterveld M, van Soolingen D, Kuijper S, Bunschoten A, Molhuizen H, Shaw R, Goyal M, et al: Simultaneous detection and strain differentiation of Mycobacterium tuberculosis for diagnosis and epidemiology. J Clin Microbiol 1997, 35(4):907-914.

15. Bazira J, Asiimwe BB, Joloba ML, Bwanga F, Matee Ml: Mycobacterium tuberculosis spoligotypes and drug susceptibility pattern of isolates from tuberculosis patients in South-Western Uganda. BMC Infect Dis 2011, 11:81.

16. Sharaf Eldin GS, Fadl-Elmula I, Ali MS, Ali AB, Salih AL, Mallard K, Bottomley C, McNerney R: Tuberculosis in Sudan: a study of Mycobacterium tuberculosis strain genotype and susceptibility to anti-tuberculosis drugs. BMC Infect Dis 2011, 11:219.

17. Tanveer M, Hasan Z, Siddiqui AR, Ali A, Kanji A, Ghebremicheal S, Hasan R: Genotyping and drug resistance patterns of $M$. tuberculosis strains in Pakistan. BMC Infect Dis 2008, 8:171.

18. Thomas KL, Joseph S, Subbaiah T, Selkon JB: Identification of tubercle bacilli from Indian patients with pulmonary tuberculosis. Bull World Health Organ 1961, 25:747-758.

19. Canetti G, Fox W, Khomenko A, Mahler HT, Menon NK, Mitchison DA, Rist N, Smelev NA: Advances in techniques of testing mycobacterial drug sensitivity, and the use of sensitivity tests in tuberculosis control programmes. Bull World Health Organ 1969, 41(1):21-43.

20. Giraffa G, Rossetti L, Neviani E: An evaluation of chelex-based DNA purification protocols for the typing of lactic acid bacteria. J Microbiol Methods 2000, 42(2):175-184

21. Blanco-Abad V, Ansede-Bermejo J, Rodriguez-Castro A, Martinez-Urtaza J: Evaluation of different procedures for the optimized detection of Vibrio parahaemolyticus in mussels and environmental samples. Int J Food Microbiol 2009, 129(3):229-236.

22. Versalovic J, Kapur V, Koeuth T, Mazurek GH, Whittam TS, Musser JM, Lupski JR: DNA fingerprinting of pathogenic bacteria by fluorophore-enhanced repetitive sequence-based polymerase chain reaction. Arch Pathol Lab Med 1995, 119(1):23-29.

23. Brudey K, Driscoll JR, Rigouts L, Prodinger WM, Gori A, Al-Hajoj SA, Allix C, Aristimuno L, Arora J, Baumanis V, et al: Mycobacterium tuberculosis complex genetic diversity: mining the fourth international spoligotyping database (SpolDB4) for classification, population genetics and epidemiology. BMC Microbiol 2006, 6:23.

24. Baptista IM, Oelemann MC, Opromolla DV, Suffys PN: Drug resistance and genotypes of strains of Mycobacterium tuberculosis isolated from human immunodeficiency virus-infected and non-infected tuberculosis patients in Bauru, Sao Paulo, Brazil. Mem Inst Oswaldo Cruz 2002, 97(8):1147-1152.

25. MINSA: Programa Naciona para el control de la turberculosis. Panama: Notas informativa MINSA; 2008.

26. Amukoye E: Multi drug resistant tuberculosis: a challenge in the management of tuberculosis. African J Health Sci 2008, 15(1):6-13.

27. Chia BS, Lanzas F, Rifat D, Herrera A, Kim EY, Sailer C, Torres-Chavolla E, Narayanaswamy P, Einarsson V, Bravo J, et al: Use of multiplex allelespecific polymerase chain reaction (MAS-PCR) to detect multidrugresistant tuberculosis in Panama. PLoS One 2012, 7(7):e40456.

28. Hu Y, Hoffner S, Jiang W, Wang W, Xu B: Extensive transmission of isoniazid resistant $M$. tuberculosis and its association with increased multidrug-resistant TB in two rural counties of eastern China: a molecular epidemiological study. BMC Infect Dis 2010, 10:43.

29. Bryant JM, Schurch AC, van Deutekom H, Harris SR, de Beer JL, de Jager $V$, Kremer K, van Hijum SA, Siezen RJ, Borgdorff M, et al: Inferring patient to patient transmission of Mycobacterium tuberculosis from whole genome sequencing data. BMC Infect Dis 2013, 13(1):110.

30. de Beer JL, van Ingen J, de Vries G, Erkens C, Sebek M, Mulder A, Sloot R, van den Brandt AM, Enaimi M, Kremer K, et al: Comparative study of IS6110 restriction fragment length polymorphism and variable-number 
tandem-repeat typing of Mycobacterium tuberculosis isolates in the Netherlands, based on a 5-year nationwide survey. J Clin Microbiol 2013, 51(4):1193-1198.

31. Ferro BE, Nieto LM, Rozo JC, Forero L, van Soolingen D: Multidrug-resistant Mycobacterium tuberculosis, Southwestern Colombia. Emerg Infect Dis 2011, 17(7):1259-1262.

doi:10.1186/1471-2334-13-442

Cite this article as: Rosas et al:: High clustering rates of multidrugresistant Mycobacterium tuberculosis genotypes in Panama. BMC

Infectious Diseases 2013 13:442.

\section{Submit your next manuscript to BioMed Central and take full advantage of:}

- Convenient online submission

- Thorough peer review

- No space constraints or color figure charges

- Immediate publication on acceptance

- Inclusion in PubMed, CAS, Scopus and Google Scholar

- Research which is freely available for redistribution 